lesions than the patients in earlier reports of either coronary or femoral atheroma. Thus Knight et $a l^{7}$ found regression of coronary lesions in only three out of 22 patients with hypercholesterolaemia after surgical partial ileal bypass had produced an average $40 \%$ lowering of serum cholesterol concentrations.

The message seems abundantly clear.

${ }^{1}$ Bruschke, A V G, Proudfit, W L, and Sones, F M, Circulation, 1973, 47, 1154

2 Henderson, R R, et al, American fournal of Cardiology, 1973, 31, 785

${ }^{3}$ Gensini, G G, Esente, P, and Kelly, A, Circulation, 1974, 50, suppl 11, 98.

- Landmann, J, Kolsters, W, and Bruschke, A V G, European Fournal of Cardiology, 1976, 4, 475.

${ }^{5}$ Himbert, J, et al, Bulletins et Mémoires de la Société médicale des Hôpitaux de Paris, 1963, 114, 367

- Barndt, R, et al, Annals of Internal Medicine, 1977, 86, 139.

${ }^{7}$ Knight, L, et al, Surgical Forum, 1972, 23, 141.

\section{Benign multiple sclerosis}

In the older neurological articles, and even in some textbooks, it was often said that multiple sclerosis (MS) was generally fatal within 5 to 25 years of its onset. Evidence has emerged in the last 20 years that this assessment is incorrect, though many patients presenting in early adult life with progressive ataxic paraparesis or with signs of multiple lesions and more especially those with severe cerebellar ataxia have a worse prognosis than average. ${ }^{1}$ However, McAlpine ${ }^{2}$ drew attention to the existence of a benign form of the disease, and this possibility was later emphasised by Mackay and Hirano. ${ }^{3}$ When retrobulbar neuritis is the first symptom the next may not follow for many years, and Brain ${ }^{4}$ mentioned patients with remissions of $13,15,17$, and 19 years respectively after an attack of retrobulbar neuritis, and of 20 and 25 years after another symptom, before the disease recurred. McAlpine $e t a l^{5}$ have suggested that a remission may last for a lifetime; in other words, an occasional patient may recover permanently from his first attack.

In the illustrative case reports selected by Mackay and Hirano ${ }^{3}$ patients could be divided into three categories: MS attenuated in midcourse; MS with early arrest of the disease; and clinically silent MS. They described patients "in which subjective symptoms were ignored or forgotten and any few and scattered neurological signs served only to puzzle the casual clinician by their inadequacy for a diagnosis." They discussed some of their own cases and some reported by others in which typical plaques had been found in the central nervous system in patients dying from other causes and in whom MS had not been suspected in life. In fact such a course of events is not infrequent, as has been shown by $\mathrm{Vuia}^{6}$ in a recent report of three cases. In the first of these a patient suffered transient difficulty in walking with dizziness and diplopia in 1942 and a brief minor recurrence of similar symptoms in July 1975. He died of carcinoma in December 1975, and old plaques characteristic of MS were found in his brain and spinal cord at necropsy. Of the other two patients, where again the pathological changes observed post mortem were characteristic, one had had only minor recurrent symptoms on two occasions over some 20 years and was not neurologically disabled at the time of death, while the other had suffered similar minimal neurological symptoms resulting from his MS but had eventually died as a consequence of cerebral and visceral arteriopathy.
Clearly, then, MS is a disease which frequently runs an exceptionally benign course. ${ }^{78}$ Kurtzke et al ${ }^{9}$ found that $69^{\circ} \%$ of men patients lived more than 25 and $50^{\circ}$ o more than 35 years after the onset, while death from the disease seemed to occur somewhat earlier in women than in men patients ${ }^{10}$; for men the peak age of death was between 65 and 84 years. It remains to be asked if there is any way to predict in an individual patient that the disease is likely to run a benign course. In many of the cases that prove benign the first lesion is retrobulbar neuritis, followed by a prolonged period of remission before other neurological symptoms develop; alternatively, an onset with sensory as distinct from motor symptoms seems to carry a good prognosis." Even in patients who suffer more frequent relapses and remissions, if their activity is relatively unrestricted within 5 to 10 years after the first limb symptoms the prognosis seems reasonably good. No rule is absolute, for one of the characteristics of this disease is its unpredictability, but clearly patients and their relatives should recognise how exceptionally benign the course of the illness may often be.

${ }^{1}$ Leibowitz, U, Kahana, E, and Alter, M, Lancet, 1969, 2, 1323.

2 McAlpine, D, Brain, 1961, 84, 186.

${ }^{3}$ Mackay, R P, and Hirano, A, Archives of Neurology (Chicago), 1967, 17, 588

4 Walton, J N, Brain's Diseases of the Nervous System, 8th edn. London, Oxford University Press, 1977.

5 McAlpine, D, Lumsden, C E, and Acheson, E D, Multiple Sclerosis: $A$ Reappraisal, 2nd edn. Edinburgh and London, Churchill Livingstone, 1972.

6 Vuia, O, Acta Neurological Scandinavica, 1977, 55, 289.

- Percy, A K, et al, Archives of Neurology (Chicago), 1971, 25, 105.

8 British Medical Journal, 1972, 1, 392.

9 Kurtzke, J F, et al, Archives of Neurology (Chicago), 1970, 22, 215.

10 Kurtzke, J F, Acta Neurologica Scandinavica, 1972, 48, 148.

\section{Stress incontinence}

Stress incontinence is at the borderland of gynaecology and urology. For many years it was the province of the gynaecologist because of its association-now questioned-with vaginal prolapse. More recently, however, new techniques of urodynamics have made the urologist's opinion vital. Furthermore, we now know that the clinician may wrongly interpret urge incontinence as stress incontinence, with very poor results from surgery.

A carefully taken history and full examination are the first essentials of management. Patients with urge incontinence due to instability of the detrusor muscle need to be recognised; for women with this syndrome and a vaginal prolapse requiring surgery in its own right must be warned that their distressing incontinence may be unaffected by the operation. Other patients may be found to have chronic retention, and urine culture may disclose urinary infection.

What, however, of the women whose symptoms are due to stress incontinence, and in particular, what is the mechanical problem? We know that there is no intrinsic permanent damage to the sphincteric mechanism, ${ }^{1}$ though there is loss of support for the vesicourethral junction. Moreover, while the total length of the urethra probably does not influence matters, ${ }^{2}$ the length of its intra-abdominal portion above the pelvic floor may be critical. ${ }^{3}$

The concept of "loss of the urethrovesical angle" was described by Jeffcoate and Francis ${ }^{4}$ from their studies of single static voiding radiographs. Since then the introduction 
of voiding ciné cystograms has given us more information; while cough-incompetence of the bladder neck may be the primary abnormality, the competence of the distal urethra also plays an important part in determining which women have stress incontinence.5 Clearly, too, the external sphincter has an important role, as does the intrinsic tone of the urethra.

On current theories, then, the vesicourethral sphincteric mechanism is thought to become less efficient as the region of the bladder neck area descends; and as this region moves distally through the pelvic floor the reflex shut-off action on the distal urethra becomes ineffective. Urine may then be propelled forcibly through the open bladder neck by raised intra-abdominal pressure.

Ciné pressure-flow studies may be necessary to identify the nature of the incontinence in patients with an "unstable bladder." Here a cough may not only induce primary stress leakage but also urge incontinence. Even with careful historytaking it may be difficult to distinguish women with this syndrome-especially those who are incontinent when rising from chairs or when walking and who may not describe urgency. Ciné studies will also show when there is a vaginal prolapse not easily apparent in the patient who is lying down.

What should be the plan for patients with stress incontinence? Firstly, those with gross vaginal prolapse and stress incontinence clearly still need an appropriate vaginal repair. At one time the proportion of women with stress incontinence thought to have an associated vaginal prolapse was put at $80-90 \%$ : in fact, the figure is probably nearer $50^{\circ}{ }_{0}$. While a vaginal repair offers an $80-90 \%$ chance of complete cure of symptoms of the prolapse in correctly selected patients, the cure of stress incontinence is a fortuitous bonus. Factors other than the abnormal vaginal anatomy affect continence, and urinary symptoms may continue unabated in a small group of these women despite a perfect repair. ${ }^{6}$ A good result from both aspects can be expected in $80-85 \%$ of cases, but long-term follow-up suggests that the failure rate may rise with time.

In those patients without any serious degree of vaginal prolapse, ideally ciné voiding studies ${ }^{5}$ should be performed to determine the exact cause. Should these facilities not be readily available, a careful history and a clear demonstration of cough-induced stress incontinence provide an acceptable clinical assessment. The most usual operation remains the well-tried abdominal correction by simple vesicourethral suspension described in 1949 by Marshall, Marchetti, and Krantz. $^{8}$ Marshall $^{9}$ claimed satisfactory results in $90 \%$ of patients so treated.

Recently surgeons have been looking for ways of achieving the anatomical results of the Marshall-Marchetti manoeuvre by less major procedures, all of which stem from Pereyra's operation. ${ }^{10}$ In this, sutures are placed either side of the proximal urethra by a cannula and trocar passed from suprapubic stab incisions through to the vagina. Stamey and his colleagues at Stanford ${ }^{311}$ monitor the placement of the sutures by endoscopy during surgery-both to confirm that the needle passes outside the bladder and urethra and to allow accurate placement and adjustment of the sutures at the vesical neck. A final endoscopic assessment with the bladder distended then confirms that its neck has been closed. Cobb and Ragde ${ }^{12}$ have described an even more simple and effective variant of this procedure using double-pronged needles for placing the bladder neck sutures. When previous operations have been unsuccessful Morgan and Farrow ${ }^{13}$ have claimed excellent results from a combined two-team abdominal and vaginal approach. They mobilise the bladder and urethra, releasing all scar tissue, and insert a wide band of inert polypropylene mesh as a sling.

Whatever the surgical technique employed, however, there remain a group of women-at least $10 \%$ of any series-who derive little or no benefit from surgery. It is in this group that urodynamic ciné voiding studies are essential. Investigation may show that still further surgery may help in cases in which sutures have either been incorrectly placed or have cut through poor tissues. Women with unstable bladderswho will be disenchanted with the failure of surgical treatment - may be helped by anticholinergic agents, such as propantheline or by vesical overdistension. The women, often elderly, with chronic retention presenting with stress incontinence may be greatly helped by intravesical administration of prostaglandin. ${ }^{14}$ Rarely, urethral stenosis may be found: this will respond to urethral dilatation.

Finally, there are a few women in whom there is no apparent underlying vesical problem and in whom surgery has completely failed: for these an artificial sphincter now offers relief from intractable permanent urinary incontinence.

' Tanagho, E A, British fournal of Urology, 1974, 46, 295.

2 Stamey, T A, Schaeffer, A J, and Condy, M, Surgery, Gynecology and Obstetrics, 1975, 140, 355 .

${ }^{3}$ Lloyd-Davies, R W, and Hinman, F Jr, Fournal of Urology, 1971, 105, 802.

${ }^{4}$ Francis, W J S, and Jeffcoate, T N A, in Modern Trends in Gynaecology 3, ed R J Kellar, p 72. London, Butterworth, 1963.

${ }^{5}$ Bates, C P, Whiteside, C G, and Turner-Warwick, R T, British fournal of Urology, 1970, 42, 714.

${ }^{6}$ Jeffcoate, T N A, Principles of Gynaecology, 4th edn, chap 42. London, Butterworth, 1975.

' Farrar, D J, et al, Surgery, Gynecology and Obstetrics, 1975, 141, 875.

${ }^{8}$ Marshall, V F, Marchetti, A A, and Krantz, K E, Surgery, Gynecology and Obstetrics, 1949, 88, 509.

9 Marshall, V F, Medical Record and Annals, 1953, 47, 647.

10 Pereyra, A J, Western fournal of Surgery, Obstetrics and Gynecology, 1959, 67, 223.

11 Stamey, T A, Surgery, Gynecology and Obstetrics, 1973, 136, 547.

${ }^{12}$ Cobb, O E, and Ragde, H, fournal of Urology, 1977, in press.

${ }^{13}$ Morgan, J E, and Farrow, G A, British fournal of Urology, 1977, 49, 37.

Bultitude, M T, Hills, N M, and Shuttleworth, K E D, British fournal of Urology, 1976, 48, 631 .

\section{Activity and recurrent hernia}

Wakeley's" assertion that "a surgeon can do more for the community by operating on hernia cases than on cases of malignant disease" remains economically sound. Groin hernias occur in $3-8 \%$ of the population ${ }^{2}$ and account for $12.5 \%$ of all surgical admissions. ${ }^{3}$ Now that the most efficient use of expensive hospital resources has become essential the traditional insistence on two weeks' absolute bed rest after herniorrhaphy ${ }^{1}$ has become an anachronism. Its assumption that early ambulation provoked recurrence has been challenged in numerous recent studies.

The reported incidence of recurrence after herniorrhaphy varies enormously. The monotonous excellence claimed in personal series is in obvious contrast with the depressing results of impersonal statistical reviews. ${ }^{4}$ Realistic recurrence rates in a general surgical unit are $5-10 \%$ for indirect inguinal, $15-20 \%$ for direct inguinal, $30 \%$ for recurrent inguinal, and $10 \%$ for femoral hernias. ${ }^{25-7}$ Only half of recurrences are apparent at five years, so that figures based on short follow-up are meaningless. ${ }^{8}$ Many of the discrepancies in reported recurrence rates may be due to the wide range of operations employed, but other factors are known to have a direct effect on recurrence irrespective of the method of 